\title{
Age-Related Changes in Pulmonary Venous Epinephrine Concentration, and Pulmonary Vascular Response after Intratracheal Epinephrine
}

\author{
CHARLES J. MULLETT, JIAN-QIANG KONG, JUDITH T. ROMANO, AND MARK J. POLAK \\ Departments of Pediatrics [C.M., J.T.R., M.J.P.] and Pharmacology/Toxicology [J-Q.K.], West Virginia \\ University School of Medicine, Morgantown, West Virginia 26506
}

\begin{abstract}
Using an isolated salt-perfused lung model in rabbits from 1 to $21 \mathrm{~d}$ of age, we measured the concentration of epinephrine in the pulmonary venous drainage and the pulmonary vascular response after a single dose of intratracheal epinephrine $(0.1 \mu \mathrm{g} / \mathrm{g}$ body weight). Lungs from 30 rabbits were isolated, ventilated, and perfused at one of four age groups ( $n=7-8$ per group). After ventilation/perfusion was judged to be stable, saline control was injected into the trachea, changes in pulmonary pressure were recorded, and perfusate was collected for $45 \mathrm{~s}$. After restabilization, epinephrine was injected into the trachea, changes in pulmonary vascular pressure were recorded, and perfusate was collected for $45 \mathrm{~s} \times$ two aliquots. Perfusate epinephrine concentrations were determined by HPLC. Little epinephrine was detected in the perfusate after control over all age groups, and little vascular response was noted. There was a significant age-related increase in perfusate epinephrine concentration as well as an age-related increase in vascular response (increased PAP), with the maximum epinephrine concentration and change in PAP noted at 14-21 d Igroup $4=(1.72 \pm 0.42)$ $\times 10^{4} \mathrm{pmol} / \mathrm{L}$. Also, in rabbits less than $6 \mathrm{~d}$ of age, deposition of epinephrine into the pulmonary venous drainage was delayed. In the rabbit model, the concentration of epinephrine reaching the heart via pulmonary circulation after intratracheal injection is, at birth, very low, and the pulmonary vascular response is diminished. Both increase as a function of age until 14-21 d of age. These findings may have clinical importance in human neonatal resuscitation endeavors. (Pediatr Res 31: 458-461, 1992)
\end{abstract}

\section{Abbreviations}

PAP, Pulmonary artery pressure

ANOVA, analysis of variance

Epinephrine is used to stimulate the failing heart during resuscitation attempts in adults and infants. Clinically, both i.v. and intratracheal administration have been used with success (1), although to achieve adequate epinephrine levels in the blood a 10 -fold higher dose is required for intratracheal compared with i.v. administration (1-3). Little is known concerning the most appropriate manner of delivery in the neonate. Administration

Received September 16, 1991; accepted January 16, 1992.

Correspondence: Mark J. Polak, M.D., Department of Pediatrics, Health Science Center, North, West Virginia University School of Medicine, Morgantown, WV 26506. of the drug via an endotracheal tube is accepted by the Neonatal Resuscitation Program criteria sponsored by the American Heart Association and the American Academy of Pediatrics (4). The pharmacokinetics and physiologic effects of intratracheal epinephrine in neonates have not been well researched. There is evidence that in newborn mammals the adrenergic system is immature in terms of number of receptors, the ability of the receptor to bind with a ligand, and the ability to generate a measurable response (5-7), although, clinically, newborns do respond to infusions of catecholamines with changes in blood pressure and heart rate $(8,9)$. With intratracheal injection, one of the factors that would influence any physiologic action on the heart is the ability of the drug to diffuse from the airway into the pulmonary venous drainage.

We hypothesized that the efficacy of intratracheal epinephrine as a resuscitation drug would be influenced, at least in part, by diffusion of the drug from the airway into pulmonary vascular space. We wanted to examine whether the amount and rate of diffusion of epinephrine from the airway into the pulmonary venous drainage changes as a function of age, related at least in part to a postnatal maturing of the lungs. Using an isolated saltperfused lung model in rabbits from 1 to $21 \mathrm{~d}$ of age, we measured and compared the concentration of epinephrine in the pulmonary venous drainage, as well as the pulmonary vascular response (change in PAP), after a single dose of epinephrine $(0.1 \mu \mathrm{g} / \mathrm{g}$ body weight) injected intratracheally.

\section{MATERIALS AND METHODS}

The protocol was approved by the Animal Care and Use Committee at West Virginia University School of Medicine. Timed pregnant New Zealand White rabbit does were allowed to deliver spontaneously at $31 \mathrm{~d}$ gestation (full term). The pups were nested with their mothers and assigned to perfusion groups based on age: $1-3 \mathrm{~d}, 4-6 \mathrm{~d}, 7-13 \mathrm{~d}$, and 14-21 d. On the day of perfusion, the rabbit pups were removed from the nest, taken to the laboratory, and weighed. The animals were instrumented for perfusion based on a modification of the methods described by Polak et al. (10) and Knight et al. (11).

Briefly, the rabbit pups were anesthetized with $0.05 \mathrm{mg} / \mathrm{g}$ pentobarbital injected intraperitoneally. A tracheostomy was performed, and mechanical ventilation begun using a Harvard rodent ventilator (room air, rate $=20$ breaths $/ \mathrm{min}$, tidal volume $=2 \mathrm{c}^{3}$ ). The heart and lungs were exposed via a median sternotomy, heparin $(100 \mathrm{U} / 100 \mathrm{~g})$ was injected into the right ventricle, and a ligature was placed loosely around the pulmonic and aortic trunks. A perfusion cannula was inserted into the main pulmonary artery through a small incision in the right ventricular outflow tract. The ligature was tightened around both the pulmonary artery and aorta, and an infusion begun with Earl's 
balanced salt solution, with $16 \mathrm{mM} \mathrm{NaHCO}_{3}$ added ( $\mathrm{pH} 7.40$ ). The tip of the left ventricle was quickly excised and a second cannula was introduced into the left atrium, retrograde through the mitral valve, and fixed into position with a ligature around both ventricles. The ductus arteriosus was identified and ligated.

The perfusate was pumped from a syringe reservoir at a constant flow rate $\left[2 \mathrm{~mL} /\left(\mathrm{min} \cdot 50 \mathrm{~g}\right.\right.$ body weight $\left.\left.{ }^{-1}\right)\right]$ through a heat exchanger (temperature $=37^{\circ} \mathrm{C}$ ) and into the pulmonary artery, where it circulated through the lungs and returned to the reservoir via the left atrial catheter. Mean PAP was continuously measured by a pressure transducer connected to a physiologic recorder.

The protocol was designed to investigate deposition of exogenous epinephrine into the pulmonary vasculature after intratracheal injection, as a function of age. The physiologic effect of intratracheal epinephrine, in terms of change in PAP, was also measured. After instrumentation, the flow rate was adjusted, and the lung preparation was allowed to stabilize in terms of PAP, perfusion temperature $\left(37^{\circ} \mathrm{C}\right)$, and $\mathrm{pH}(7.40)$. After a 15-min stabilization period, $0.01 \mathrm{~mL} / \mathrm{g}$ physiologic saline was injected into the trachea as a control. Mechanical ventilation was interrupted during the intratracheal injection, then resumed immediately with the same ventilator settings. Perfusate was collected from the pulmonary outflow catheter for $45 \mathrm{~s}$ (Fx.1), and any change in pulmonary vascular pressure was recorded. After a 15min recovery and restabilization period, epinephrine $(0.01 \mathrm{~mL} /$ $\mathrm{g}$ body weight, $0.1 \mathrm{mg} / \mathrm{mL}$ ) was injected into the trachea. This dose was chosen based on recommendations of the American Heart Association/American Academy of Pediatrics Neonatal Resuscitation Program criteria (4). Mechanical ventilation was maintained with only a brief interruption for intratracheal injection, changes in PAP were recorded, and perfusate was collected in timed aliquots 0-45 s (Fx.2) and 46-90 s (Fx.3) after epinephrine injection. The perfusate samples were titrated to $\mathrm{pH}=1.0$ with $10 \mathrm{~N}$ perchloric acid and frozen to $-4^{\circ} \mathrm{C}$. At the conclusion of each experiment, the lungs were removed, weighed, dried in a drying oven, and reweighed. Wet to dry lung weight ratios were calculated as a determination of lung edema. From our previous experience, the wet/dry weight ratio ranges from 4 to 8 under conditions where edema development is minimal $(10,12)$. Concentration of epinephrine from all perfusate samples was determined by HPLC with a Waters $\mu$ Bondapak $\mathrm{C}_{18} 3.9 \times 300 \mathrm{~mm}$ analytical column (Waters Co., Milford, MA) and electrochemical detection. With this equipment, epinephrine and metabolites can be measured to the $\mathrm{pg} / \mathrm{mL}$ range (13).

Regression curves were constructed for the mean concentration of epinephrine in the perfusate versus rabbit age group ( $n=$ 7-8 per age group). Curves were generated for: 1) Fx.1, saline control; 2) Fx.2, 0-45 s after epinephrine injection; 3) Fx.3, 46$90 \mathrm{~s}$ after epinephrine injection. The perfusate concentration versus age group curves were analyzed by regression analysis. Comparisons of perfusate epinephrine concentrations versus age groups were made using single-factor ANOVA. Comparisons of epinephrine concentrations from Fx.1, Fx.2, and Fx.3, within each age group were made by single-factor ANOVA for repeated measures.

Mean values for $\triangle \mathrm{PAP}$ after saline control and epinephrine from each age group were compared within each age group by single-factor ANOVA for repeated measures and across age groups by single-factor ANOVA.

All data are presented as means \pm SEM.

\section{RESULTS}

A total of 30 separate experiments were performed, one each for 30 rabbits of various ages. Rabbit age groups, weight, perfusate flow rate, wet/dry lung weight ratio, and baseline PAP as well as the changes in PAP in response to saline control and epinephrine injection are detailed in Table 1 . The change in PAP after saline injection was similar in all age groups and essentially unchanged from baseline (i.e. $\triangle \mathrm{PAP}=0$ ). After intratracheal epinephrine injection, there was a significant increase in PAP consistent with vasoconstriction. In addition, we noted an agerelated change in the degree of PAP increase $(p=0.08$ across all four age groups, $p=0.047$ between groups 1 and $4, p=0.02$ between groups 2 and 4).

The epinephrine concentration-age group curves for Fx.1, Fx.2, and Fx.3 are graphically represented in Figure 1. After saline control (Fx.1), very little epinephrine was found in the perfusate from age groups 1,2 , or 3 . This level of presumably endogenous epinephrine increases slightly $(p=0.06)$ by age group $4(14-21 \mathrm{~d})$ to $(0.21 \pm 0.12) \times 10^{4} \mathrm{pmol} / \mathrm{L}(38.8 \pm 22.8$ $\mathrm{ng} / \mathrm{mL})$.

As noted previously, perfusate was collected in two aliquots after epinephrine injection. Perfusate collected for the first $45 \mathrm{~s}$ after intratracheal epinephrine (Fx.2) showed a significant $(p<$ 0.001 ) age-related increase in epinephrine from $(0.16 \pm 0.06) \times$ $10^{4} \mathrm{pmol} / \mathrm{L}(29.1 \pm 10.6 \mathrm{ng} / \mathrm{mL})$ in age group 1 to $(1.72 \pm 0.42)$ $\times 10^{4} \mathrm{pmol} / \mathrm{L}(315.1 \pm 76.8 \mathrm{ng} / \mathrm{mL})$ in age group 4 . There was also an age-related increase in epinephrine concentration in the perfusate collected from 46 to $90 \mathrm{~s}$ after epinephrine injection (Fx.3), from $(0.33 \pm 0.09) \times 10^{4} \mathrm{pmol} / \mathrm{L}(60.4 \pm 16.2 \mathrm{ng} / \mathrm{mL})$ in age group 1 to $(1.33 \pm 0.39) \times 10^{4} \mathrm{pmol} / \mathrm{L}(243.2 \pm 70.9 \mathrm{ng} /$ $\mathrm{mL})$ in age group $4(p=0.03)$.

Within each age group, the perfusate epinephrine concentration in Fx.2 and Fx.3 was significantly $(p<0.05)$ greater than that in Fx.1 as assessed by single-factor ANOVA for repeated measures. Furthermore, in age groups 1 and 2, the epinephrine concentration in Fx.3 was significantly higher than that in Fx.2, suggesting a delay in diffusion of epinephrine from the airway into the pulmonary vasculature. In age groups 3 and 4, epinephrine concentrations from Fx.2 and Fx. 3 were not significantly different.

\section{DISCUSSION}

The use of neonatal rabbits combined with an isolated perfused lung preparation has proved to be an effective method of studying pulmonary pharmacodynamics $(10,14)$. The isolated perfused lung has also proved to be suitable for the study of organ-specific responses to pharmacologic manipulation (i.e. adrenergic stimulation) $(10,15)$. Normal cytoarchitecture, cell to cell interactions, and the relationships between the airways, alveoli, and pulmonary vasculature are preserved. With the environment, perfusate composition, flow, ventilation, temperature, and $\mathrm{pH}$ kept constant in all experiments, the sole variables are related to animal age (increase in size and maturity). Using this simple model, we have shown that during the first several days of life the concentration of epinephrine found in the pulmonary venous drainage immediately after an intratracheal injection of epinephrine is quite low, but increases as a function of age for the first $2-3$ wk of life. It is also apparent that during the first week of life there seems to be a delay in diffusion of the epinephrine into the pulmonary vasculature. A physiologic effect of intratracheal epinephrine on the pulmonary vasculature (increase in PAP) is noted in all age groups, and also shows a significant age-related change.

The amount of epinephrine that reaches the pulmonary vasculature, as well as the rate of drug diffusion, is influenced by several factors that may account for these differences. These variables are the lung surface area over which the drug may be deposited and the barriers, or lack thereof, to diffusion of the drug into the vasculature. In the neonatal animal, the lungs can maintain extrauterine life but cannot be considered to be mature (16-18). Respiration takes place primarily in respiratory bronchi and a few terminal alveoli. The respiratory surface area:dead space surface area ratio is quite low. In addition, the epithelial linings of respiratory bronchi and alveoli are thickened compared with those of adult lungs, causing an additional barrier to drug diffusion (19). On the vascular side, the pulmonary vascular 
Table 1. Age group characteristics, lung stability data, and changes in PAP after saline (control) or epinephrine*

\begin{tabular}{cccccccc}
\hline Group & $n$ & $\begin{array}{c}\text { Age } \\
(\mathrm{d})\end{array}$ & Weight $(\mathrm{g})$ & $\begin{array}{c}\text { Baseline PAP } \\
(\mathrm{mm} \mathrm{Hg})\end{array}$ & $\begin{array}{c}\text { Saline } \Delta \text { PAP } \\
(\mathrm{mm} \mathrm{Hg})\end{array}$ & $\begin{array}{c}\text { Epi } \Delta \text { PAP } \\
(\mathrm{mm} \mathrm{Hg})\end{array}$ & $\begin{array}{c}\text { Wet/dry } \\
(\mathrm{mm} \mathrm{Hg})\end{array}$ \\
\hline 1 & 8 & $1-3$ & $63.2 \pm 4.1$ & $8.3 \pm 0.8$ & $0.04 \pm 0.03$ & $0.23 \pm 0.12 \ddagger$ & $3.5 \pm 0.1$ \\
2 & 7 & $4-6$ & $80.8 \pm 4.4$ & $9.2 \pm 1.0$ & $0.04 \pm 0.02$ & $0.23 \pm 0.08 \ddagger$ & $4.3 \pm 0.4$ \\
3 & 8 & $7-13$ & $185.5 \pm 17.7$ & $7.7 \pm 0.9$ & $0.03 \pm 0.06$ & $0.38 \pm 0.10$ & $4.9 \pm 0.6$ \\
4 & 7 & $14-21$ & $240.4 \pm 13.7$ & $8.0 \pm 0.7$ & $0.05 \pm 0.04$ & $0.60 \pm 0.11 \ddagger$ & $4.7 \pm 0.5$ \\
\hline
\end{tabular}

* All data presented as mean \pm SEM. Epi, epinephrine.

$\dagger$ At all age groups, saline $\triangle \mathrm{PAP}$ is not different from baseline $(\triangle \mathrm{PAP}=0)$ and Epi $\triangle \mathrm{PAP}$ is significantly different $(p<0.05)$ from saline $\triangle \mathrm{PAP}$ by ANOVA for repeated measures.

$\ddagger$ Significant $(p \leq 0.05)$ difference between groups 1 and 4 and between groups 2 and 4 as determined by single-factor ANOVA.

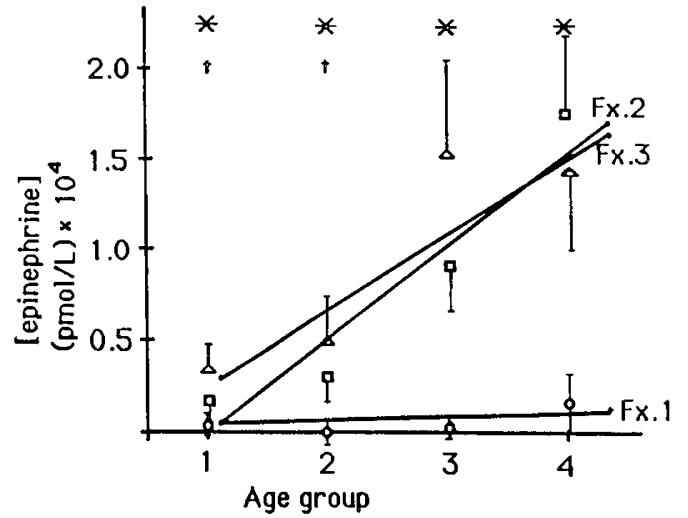

Fig. 1. Perfusate epinephrine concentrations (pmol/L $\left.\times 10^{4} \pm \mathrm{SEM}\right)$ and regression lines for Fx.1, Fx.2, and Fx.3 vs age groups (group 1, 1-3 $\mathrm{d}$; group 2, 4-6 d; group 3, 7-13 d; and group 4, 14-21 d). O, Mean perfusate epinephrine concentration from Fx.1 (saline control). There is little change until age group 4 ( $p=0.06$, group $1 \mathrm{vs}$ group 4 by onefactor ANOVA). Regression equation: [epinephrine] $=0.12$ (age group) $-0.21, r^{2}=0.13$. $\square$, Mean perfusate epinephrine concentrations from Fx.2 (0-45 s after epinephrine injection). Epinephrine concentration increases as a function of age ( $p<0.001$ by one-factor ANOVA). Regression equation: [epinephrine] $=0.96$ (age group) $-1.00, r^{2}=0.47$. $\triangle$, Mean perfusate epinephrine concentrations from Fx.3 (46-90 s after epinephrine injection). Epinephrine concentration increases as a function of age ( $p<0.03$ by one-factor ANOVA). Regression equation: [epinephrine $]=0.74$ (age group) $-0.16, r^{2}=0.22{ }^{*}$, Perfusate epinephrine concentrations from Fx.2 and Fx.3 are significantly different $(p<0.05)$ from those of Fx.l at all age groups by one-factor ANOVA for repeated measures. $\dagger$, Perfusate epinephrine concentrations from Fx. 3 are significantly different $(p<0.05)$ from those of Fx.2 at age groups 1 and 2 by one-factor ANOVA for repeated measures.

walls of the newborn are thick, also presenting a diffusion barrier. The wall thickness of arterioles decreases over the first $10 \mathrm{~d}$ to 2 wk of life, primarily due to vasodilation (20). Lung growth in terms of both increased surface area and maturation of endobronchial and alveolar lining cells, as well as the maturation of the pulmonary vasculature, continues well after birth (17-20).

It is likely that postnatal maturational changes in these two factors, site of drug deposition and barriers to drug diffusion, account for the age-related perfusate epinephrine concentration changes noted in our study. From experience with intratracheal injection of liquids (i.e. exogenous surfactant), it is apparent that a bolus of liquid will deposit into the deep airways and alveoli with mechanical ventilation (21). The ventilatory pressure required to deliver the liquid to the respiratory bronchi and alveoli is governed somewhat by Poiseuille's law of fluid flow through a tube, which states that resistance to flow is inversely proportional to the radius of the tube, such as the bronchi and terminal bronchi (22). Thus, at birth, with a given tidal volume and ventilatory pressure, a larger proportion of the injected epinephrine is likely to be deposited in the conducting airways compared with the older animal, where the increased radii of the rapidly growing bronchial tree is likely to permit further penetration of the drug. One may assume that in the older animals a greater fraction of the drug deposits on the more absorptive areas of the lungs.

In the young rabbits, less than 1 wk old, we also noted a significant delay in diffusion of epinephrine into the pulmonary venous drainage. This delay is also consistent with the notion that the smaller caliber of the conducting airways of these young animals inhibits penetration of the drug to the respiratory bronchioles and alveoli and that the immature lining cells may present a barrier to drug diffusion into the vascular space.

Another factor that could alter the amount of epinephrine reaching the perfusate would be metabolism of the injected epinephrine within the lung. If epinephrine metabolism was a factor, metabolites should have been detected by the HPLC (13). We noted no evidence of epinephrine metabolites in the HPLC data and as such do not believe that this can account for the alterations noted.

We also noted a significant change in the pulmonary vascular response to injected epinephrine. Several factors may be responsible for this. The depressed physiologic response may be another indication of the barriers to diffusion of the drug from the airway into the vascular space. However, these changes are also consistent with studies that have demonstrated that the adrenergic system in newborn mammals is immature in terms of number of receptors, the ability of the receptor to bind with a ligand, and the ability to generate a measurable response $(5-7)$. The adrenergic receptors and related mechanisms mature within the first several weeks of life. This factor may further influence the cardiovascular responses, or lack thereof, of intratracheal epinephrine in the neonate.

In summary, we have shown that there is an age-related change in the rate of diffusion as well as the absolute amount of epinephrine that reaches the pulmonary venous drainage after a single intratracheal epinephrine injection. Furthermore, the physiologic response to epinephrine, at least in the pulmonary vasculature, changes with age. These changes are likely to be related to the rapidly changing architecture of the neonatal lung and continuing postnatal development of the adrenergic system. Although the isolated perfused lung is a simplified model, our results may have relevance in resuscitation attempts in human neonates. One must also consider a host of other factors, including acidosis, hypoxemia, and low flow states, that may further alter the diffusion and physiologic action of epinephrine.

\section{REFERENCES}

1. Roberts JR, Greenberg MI, Knaub M, Baskin SI 1978 Comparison of the pharmacologic effects of epinephrine administered by the intravenous and endotracheal routes. J Am Coll Emerg Phys 7:260-264

2. Roberts JR, Greenberg MI, Knaub M, Kendrick ZV, Baskin SI 1979 Blood levels following an intravenous and endotracheal epinephrine administration. J Am Coll Emerg Phys 8:53-56

3. Ralston SH, Tacker WA, Showen L, Carter A, Babbs CF 1985 Endotracheal versus intravenous epinephrine during electromechanical dissociation with CPR in dogs. Ann Emerg Med 14:1044-1048

4. Bloom RS, Cropley C (ed) 1987 Textbook of Neonatal Resuscitation. American Heart Association, American Academy of Pediatrics

5. Langston C, Holder $P 1987$ Pulmonary vascular changes in infants and children. In: Will JA, Dawson CA, Weir EK, Buckner CK (eds) 1987 The Pulmonary Circulation in Health and Disease. Academic Press, Orlando, FL, pp 57-74 
6. Yamada S, Yamamura HI, Roeske WR 1980 Ontogeny of mammalian cardiac alpha ${ }_{1}$-adrenergic receptors. Eur J Pharmacol 68:217-221

7. Gauthier P, Nadeau RA, de Champlain J 1975 The development of sympathetic innervation and functional state of the cardiovascular system in newborn dogs. Can J Physiol Pharmacol 53:763-776

8. Driscoll DJ 1987 Use of ionotropic and chronotropic agents in the newborn. Clin Perinatol 14:931-950

9. Zaritsky A, Chernow B 1984 Use of catecholamines in pediatrics. J Pediatr 105:341-350

10. Polak MJ, Knight ME, Gause GE, Bucciarelli RL, Drummond W 1989 Effect of fenoldopam on preconstricted isolated salt-perfused rat lungs. J Appl Physiol 67:1076-1080

11. Knight ME, McGehee CJ, Polak MJ, Andresen TL 1991 Effect of hyperoxia on 5-hydroxytryptamine uptake by the neonatal rabbit lung. Pulm Pharmacol 4:151-157

12. Fisher AB, Dodia C, Linask J 1980 Perfusate composition and edema formation in isolated rat lungs. Exp Lung Res 1:13-21

13. Wester P, Gottfries J, Johanson K, Klinteback F, Winblad B 1987 Simultaneous liquid chromatographic determination of seventeen of the major monoamine neurotransmitters, precursers, and metabolites. J Chromatogr 415:261-274
14. Mehendale HM, Angevine LS, Ohmiya Y 1981 The isolated perfused lung: a critical evaluation. Toxicology 21:1-36

15. Brown LAS, Longmore WJ 1981 Adrenergic and cholinergic regulation of lung surfactant in the isolated perfused rat lung and in the alveolar type II cell in culture. J Biol Chem 256:66-72

16. Sadler TW (ed) 1990 Langman's Medical Embryology. Williams \& Wilkins, Baltimore, pp 226-236

17. Langston C, Thurlbeck WM 1986 Conditions altering normal lung growth and development. In: Thibeault DW, Gregory GA (eds) Neonatal Pulmonary Care. Appleton-Century-Crofts, Norwalk, CT, pp 1-32

18. Thurlbeck WM 1982 Postnatal human lung growth. Thorax 37:564-572

19. Brody JS, Vaccaro C 1979 Postnatal formation of alveoli: interstitial events and physiologic consequences. Fed Proc 38:215-223

20. Richardson JB 1987 Innervation of the pulmonary circulation: an overview. In: Will JA, Dawson CA, Weir EK, Buckner CK (eds) The Pulmonary Circulation in Health and Disease. Academic Press, Orlando, FL, pp 9-14

21. Adams FH, Towers B, Osher AB 1978 Effects of tracheal instillation of natural surfactant in premature lambs: clinical and autopsy findings. Pediatr Res $12: 841-848$

22. Olson RM 1980 Essentials of Engineering Fluid Dynamics. Harper and Row, New York 